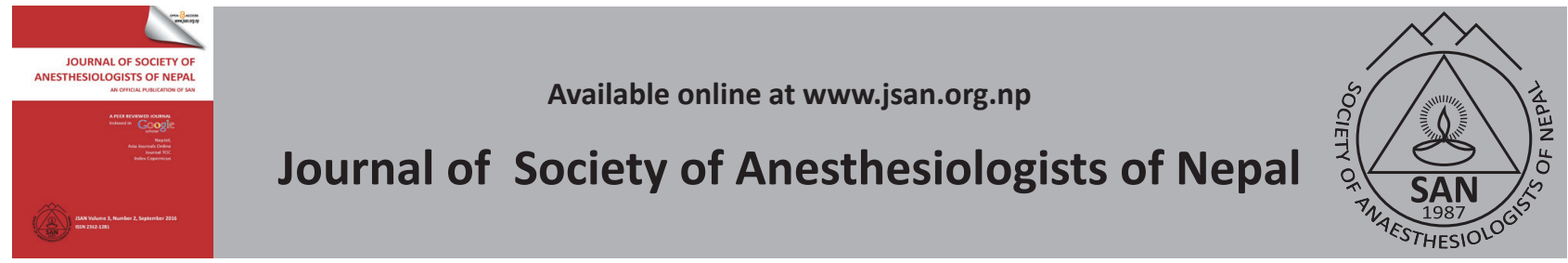

\title{
Erratum
}

\section{Erratum to Comparison of I-Gel and classic Laryngeal Mask Airway in paediatric population: a parallel group study}

$\mathrm{T}$

his erratum is issued to a recently published original

article titled "Comparison of I-Gel and classic Laryngeal Mask Airway in paediatric population: a parallel group study" in 2016, Volume 3, Number 2. The errors occurred at the time of layout editing. The following corrections were made to the originally published version.

The third author's first name Sadicchya is corrected as Sadichhya.

In page 81, method section, second paragraph, line 8 , reference number 14 is corrected as reference number 8 .

The title of table 3 has been changed as follows: mild as no resistance, moderate as some resistance and severe as moderate resistance.
The second sentence immediately following the table 3 "Majority of the patients had severe resistance during insertion of the devices," has been changed to "Majority of the patients had moderate resistance during insertion of the devices,".

\section{Reference}

Sapkota S, Hamal PK, Shah Malla S. Comparison of I-Gel and classic Laryngeal Mask Airway in paediatric population: a parallel group study. Journal of Society of Anesthesiologists of Nepal (JSAN) 2016;3(2):80-3. http:// dx.doi.org/10.3126/jsan.v3i2.15618

This work licensed under Creative Commons Attribution License CC - BY 4.0 